\title{
Homeostatic responses and growth of Leymus chinensis under incrementally increasing saline-alkali stress
}

\author{
Shujie Li ${ }^{\text {Equal first author, 1, 2, Yujin Huang }}{ }^{\text {Equal first author, 1, } 3}$, Yuefen Li ${ }^{\text {Corresp. 1, } 2}$ \\ ${ }^{1}$ College of Earth Sciences, Jilin University, Changchun 130061, China \\ 2 Key laboratory of Mineral Resources Evaluation in Northeast Asia, Ministry of Land and Resources, Changchun 130061, China \\ 3 Institute of Geographic Sciences and Natural Resources Research, CAS, Beijing 100101, China \\ Corresponding Author: Yuefen $\mathrm{Li}$ \\ Email address: yfli@jlu.edu.cn
}

Despite considerable tolerance to salt and alkali stress, Leymus chinensis populations on the southwestern Songnen Plain in northern China are threatened by increasing soil salinity and alkalinity. To explore the species' responses to saline-alkali stress, we grew it in substrates with varying concentrations of nitrogen $(\mathrm{N})$ and phosphorus $(\mathrm{P})$ while applying varying levels of saline-alkali stress (increasing in 14-, 17- or 23 -day intervals). We measured the plants' contents of $\mathrm{N}$ and $\mathrm{P}$, and the N:P ratio, and calculated their homeostasis indices $\left(H_{N}, H_{P}\right.$ and $\left.H_{N: P}\right)$ under each nutrient and saline-alkali stress treatment. The $\mathrm{N}$ content was found to be more sensitive to saline-alkali stress than the $\mathrm{P}$ content. The $\mathrm{N}$ and $\mathrm{P}$ contents were highest and the $\mathrm{N}$ : $\mathrm{P}$ ratio was stable at $\mathrm{pH} 8.4$. At both $\mathrm{pH} 8.1$ and 8.4, $H_{\mathrm{N}: \mathrm{P}}>H_{\mathrm{N}}>H_{\mathrm{p}}$, but the indices and their relations differed at other $\mathrm{pH}$ values. Exposure to saline-alkali stress for the 14-day incremental interval had weaker effects on the plants. Rapid changes in salinity-alkalinity weakened both the positive effects of the weakly alkaline conditions ( $\mathrm{pH}$ 7.5-8.4) and the negative effects of more strongly alkaline conditions ( $\mathrm{pH} 8.7$ or 9.3 ) on L. chinensis. When L. chinensis plants lack N, applying $\mathrm{N}$ fertilizer will be extremely efficient. The optimal concentrations of $\mathrm{N}$ and $\mathrm{P}$ appeared to be 16 and $1.2 \mathrm{mmol} / \mathrm{L}$, respectively. When the $L$. chinensis plants were $\mathrm{N}$ - and P-limited, the specific growth rate correlated positively with $N: P$, when limited by $N$ it correlated positively with the environmental $\mathrm{N}$ concentration, and when limited by $\mathrm{P}$ it was weakly positively correlated with the environmental $\mathrm{P}$ concentration. 


\section{INTRODUCTION}

2 Ecological stoichiometry (ES) is the study of the balances of elements and energy in ecosystems,

3 which have profound effects on living organisms, their interactions, and associated ecological

4 processes (Cambardella and Elliott, 1993; Elser et al., 2000; Güsewell, 2004; Bradshaw et al.,

5 2012). ES theory focuses primarily on elements required by all living organisms, so it can be

6 readily generalized across taxa and systems (Sanders and Taylor, 2018). A key concept is

7 homeostasis: a system's capacity to maintain constant conditions internally when external

8 conditions vary, a fundamental property of organisms (Kooijman, 1995; Cooper, 2008;

9 Halvorson et al., 2019). Characterizing both the degrees and consequences of homeostasis is important for understanding responses to environmental changes (Meunier et al., 2014;

11 Halvorson et al., 2019). In ES-based analyses, the homeostasis concept is used to infer organisms'

12 responses to changes in ratios of elemental resources, and predict their feedback effects on resources' availability through changes in the acquisition, storage, and release of nutrients,

14 particularly limiting nutrients such as nitrogen $(\mathrm{N})$ and phosphorus (P) (Halvorson et al., 2019).

A general assumption is that stoichiometric homeostasis is stronger in heterotrophs than autotrophs (Sterner and Elser, 2002), so environmental stoichiometry is believed to be reflected more closely by plant and algal stoichiometry than by animals' stoichiometry. However, Yu et al. (2011) found that homeostatic regulation of $\mathrm{N}$ and $\mathrm{P}$ varies widely in vascular plants, so the patterns and processes involved are complex and far from fully understood.

Another core concept of ES is the growth rate hypothesis (GRH), which postulates that organisms' specific growth rates correlate positively with their phosphorus (P) contents because and for many other processes including photosynthesis, respiration, enzyme production, and 
generation of ATP (Li et al., 2019). Thus, organisms with high specific growth rates have high nutrient demands and (inter alia) low tissue C:nutrient ratios, low N:P ratios, and potentially competitive advantages in high-P environments, but disadvantages in low-P environments. Hence, plants' abilities to compete for nutrients depend on both their tissue nutrient contents and life history traits (Mulder and Elser, 2009; González et al., 2010; Sanders and Taylor, 2018). ES has been widely applied in various areas of plant science, including in studies on the growth of individual plants, population dynamics, limiting elements, succession, and stability of vegetative communities (Güsewell, 2004). Soil is a key component of terrestrial ecosystems because it supports numerous ecological processes (Normand et al., 2017; Wang et al., 2018), plays crucial roles in plant growth, and directly affects plant communities' composition, stability, and succession (Wardle et al., 2004). N and P are key elements with profound effects on plants growth because they play major roles in microbial dynamics, litter decomposition, food webs, and the accumulation and cycling of nutrients in soil (Elser et al., 2003). Changes in plants' N:P ratios (inter alia) may reflect adaptations to environmental conditions (Tang et al., 2018), including (of particular interest here) salinity and alkalinity.

According to incomplete UNESCO and FAO statistics, the area of saline-alkali land is growing globally (Kerr, 2017) and amounts to $9.5438 \times 10^{8} \mathrm{hm}^{2}$, including $0.9913 \times 10^{8} \mathrm{hm}^{2}$ in China (Li et al., 2017a). This is a severe problem because salinization impairs seed germination, root extension, and plant development, resulting in land degradation, reductions in cultivated land quality, and limitation of agricultural development (Wu et al., 2016). Most saline-alkali soil in northeast China is on the Songnen Plain, and its area is increasing through grassland salinization $(\mathrm{Li}, 2000)$. The dominant species in saline-alkali grassland on the Songnen Plain is Leymus chinensis (L. chinensis), which can provide high yields of high quality gramineous 
47 forage if the salinity and alkalinity are not too severe. It can play an important role in restoring

48 saline-alkali land (Liu et al., 2014), but there is a need to reduce the salinity and alkalinity of

49

affected grassland and improve the species' yield and stress tolerance. It is therefore important to study the ecological stoichiometric homeostasis of $\mathrm{N}$ and $\mathrm{P}$, associated ecological processes, and the effects of saline-alkali stress on the growth rate and survival strategy of L. chinensis.

Previous research on saline-alkali tolerance in L. chinensis has mainly focused on physiological processes (such as the osmoregulatory roles of ions, organic acids, soluble sugars and other substances) and morphological traits (such as tiller buds, root distribution, and rhizomes' internode length and branching angles) (Zheng et al., 2017). C, N, and P dynamics in soil-L. chinensis systems have also been addressed (Li et al., 2018). The secret of $L$. chinensis adapting to saline-alkali stress has been discussed deeply from many perspectives. However, soil salinization is a long-term dynamic process, and there is relatively little information on relations between the effects of saline-alkaline stress (and of variation in its duration) and ecological stoichiometric characteristics. And few studies point out a certain range in which $L$. chinensis can adapt to lasting saline-alkali stress. We make the hypothesis that the adaptability of $L$. chinensis under different saline-alkali stress conditions is different (positive effects? or negative effects?) and there is a certain range. Here, we demonstrate that the ecological stoichiometric characteristics of $L$. chinensis are influenced by the duration of saline-alkali stress and the available concentrations of both $\mathrm{N}$ and $\mathrm{P}$.

\section{MATERIALS AND METHODS}

\section{The experimental site}

We performed experiments in an outdoor terrace on the campus of the College of Earth Sciences, Jilin University, Changchun, Jilin Province, northeast China. This is in the north temperate 
continental climatic zone, which has four distinct seasons. The mean annual temperature and precipitation are $4.8^{\circ} \mathrm{C}$ and $567 \mathrm{~mm}$, respectively, and mean winter and summer temperatures are -14 and $24{ }^{\circ} \mathrm{C}$, respectively (Zhang et al., 2017).

\section{Experimental design}

\section{Experimental preparation}

Experiments were performed from August 7 to November 6, 2017. To minimize interference from impurities in the soil, the substrate used was fine nutrient-poor sand, sieved with 10 and 75 mesh sieves and thoroughly washed with distilled water to minimize its nutrient content. To avoid effects of different soil loadings on growth of experimental plants, the sand was air-dried and equal portions were placed in plastic flowerpots (diameter $30 \mathrm{~cm}$, height $23 \mathrm{~cm}$ ). The portions were roughly equivalent to two-thirds of the pots' volume. L. chinensis seeds were immersed in water for 48 hours and air-dried in the dark to avoid dormancy and increase the germination rate, then about 100 seeds were sown evenly in each flowerpot. About seventy percent of the seeds survived, and all pots were similar with respect to the number, size, and vitality of surviving seedlings.

\section{$\mathbf{N}$ and $\mathbf{P}$ addition}

After the seeds germinated, a $200 \mathrm{ml}$ portion of Hoagland's nutrient solution with adjusted $\mathrm{N}$ and P concentrations was added to each pot once every two days. The elemental composition of Hoagland's solution is described in detail elsewhere (Li et al., 2018). In five sets of nine pots, the $\mathrm{N}$ concentration was adjusted using ammonium nitrate to establish five $\mathrm{N}$ concentration treatments $(2,4,8,16$, and $24 \mathrm{mmol} / \mathrm{L})$ in which the concentration of $\mathrm{P}$ was fixed at $1 \mathrm{mmol} / \mathrm{L}$. In another five sets of nine pots, the $\mathrm{P}$ concentration was adjusted using potassium dihydrogen phosphate to establish five $\mathrm{P}$ concentration treatments $(0.3,0.6,1.2,2.4$, and $4.8 \mathrm{mmol} / \mathrm{L})$ in 
93 which the concentration of $\mathrm{N}$ was fixed at $14 \mathrm{mmol} / \mathrm{L}$. The experiment thus involved 10 nutrient

94 treatments and a total of 90 pots (10 treatments $\times 3$ replicates $\times 3$ salinity stress intervals $)$ in a

95 randomized complete block design. The $\mathrm{N}$ and $\mathrm{P}$ concentration gradients were set on the basis of

96 previously reported results (Yu et al., 2011).

\section{Saline-alkali stress}

98 On 7 Aug 2017, after the L. chinensis plants had grown to an average height of about $15 \mathrm{~cm}$,

99 plants in triplicate pots were subjected to the saline-alkali stress treatments shown in Table 1, by

100 adding $\mathrm{NaHCO}_{3}$ to the previously described treatment solution to simulate various degrees of

101 land salinization encountered in the western regions of Jilin Province. To avoid excessively

102 stressing the plants, the $\mathrm{pH}$ was increased at intervals of 14,17 , or 23 days. The $\mathrm{pH}$ was raised

103 from 7.5 to 8.1, and then to 8.4, 8.7, and finally 9.3. Aboveground parts of L. chinensis plants

104 subjected to these treatments were harvested (cutting from the ground level) according to the

105 schedule shown in the table 1.

\section{Sample collection and testing methods}

107 Aboveground parts of L. chinensis plants were cut according to the harvesting schedule shown in

108 Table 1. The samples were rinsed with distilled water, dried with absorbent paper, deactivated

109 for $15 \mathrm{~min}$ in a dry air oven $\left(105^{\circ} \mathrm{C}\right)$ and dried for $12 \mathrm{~h}$ at $65^{\circ} \mathrm{C}$ to eliminate water completely.

110 After cooling the samples to room temperature, they were weighed, crushed, screened with a 100

111 mesh sieve, and finally quartered. The resulting sub-samples were then packed in sealed bags for 112 analysis.

113 Total $\mathrm{N}$ and total $\mathrm{P}$ in the L. chinensis samples were respectively determined by Chinese

114 standard methods LY/T 1269-1999 (using a SAN++ Continuous Flow Analyzer; Skalar,

115 Netherlands) and LY/T 1270-1999 (using an ICPS-7500 inductively coupled plasma atomic 
116 emission spectrometer; Shimadzu, Kyoto, Japan).

\section{Data analysis}

118 The acquired data were statistically analyzed using SPSS 24 (SPSS Inc., USA). Homeostasis

119 indices were calculated using the stoichiometric homeostasis model $y=c x^{\frac{1}{H}}$. Here, $x$ is the 120 measured content of an element in the soil, $y$ is the measured content of the same element in $L$.

121 chinensis, $c$ is a constant coefficient, and $H$ is the homeostasis index. The results were visualized

122 using Sigmaplot 12.5 (Systat Software, Inc.). We calculated specific growth rates based on

123 recorded changes in dry mass and instantaneous growth rates using the equation $u=\ln \left(M_{t} / M_{0}\right) / t$,

124 where $u$ is the specific growth rate $\left(\right.$ day $\left.^{-1}\right), M_{t}$ and $M_{0}$, are the final and initial dry mass,

125 respectively, and $t$ is experiment duration in days. Details of several statistical analyses are

126 included in Appendix 1 and Appendix 2.

127 RESULTS

128

129

130

131

132

133

134

135

136

137

138

\section{Effects of incremental increases in saline-alkali stress on $N, P$ contents and $N: P$ ratios}

The 14-day stress increment yielded the highest $\mathrm{N}$ and $\mathrm{P}$ contents in the plants when the $\mathrm{N}$ concentration in the substrate was low $(2-8 \mathrm{mmol} / \mathrm{L})$, but not when the $\mathrm{N}$ concentration in the substrate was higher $(16$ or $24 \mathrm{mmol} / \mathrm{L})$. The variation in the $\mathrm{N}$ and $\mathrm{P}$ contents, and the $\mathrm{N}: \mathrm{P}$ ratio, was similar under all three stress intervals: the $\mathrm{N}$ content and N:P ratio were highest with 17-day intervals, while the P content was highest with 14-day intervals (Fig. 1).

\section{Homeostasis characteristics of $L$. chinensis}

The homeostasis index of $\mathrm{N}\left(H_{N}\right)$ in L. chinensis ranged from 2.35 to 7.25 , and first rose then fell as salinity-alkalinity increased, independently of interval length (Fig. 2). Under the 14-, 17- and 23-day intervals, $H_{\mathrm{N}}$ ranges were $3.10-7.25,2.35-5.36$ and 3.19-3.87, respectively. It was consistently highest at $\mathrm{pH} 8.4$, and higher at $\mathrm{pH} 8.1$ and 8.7 than at $\mathrm{pH} 7.5$ and 9.3 (Table 2). 
139 Under the 14-day stress intervals, the changes in $H_{\mathrm{N}}$ were moderate, and $H_{\mathrm{N}}$ was high at all $\mathrm{pH}$ 140 values. The index was lower at both $\mathrm{pH} 8.1$ and 8.7 under the 17- and 23-day intervals.

141 Under our treatments, $H_{P}$ of L. chinensis ranged from 2.60 to 5.33. Under all three saline-

142 alkali stress intervals, it first rose and then declined (Fig. 2). Under the 14-, 17-, and 23-day

143 saline-alkali stress intervals, the ranges of $H_{P}$ were 2.84-5.33, 2.65-4.90 and 2.60-4.10,

144 respectively, and the highest values of $H_{P}$ occurred at $\mathrm{pH} 8.1,8.7$, and 8.1, respectively (Table 2).

145 At $\mathrm{pH} 8.1, H_{P}$ was significantly higher under 14-day intervals than under longer intervals. At $\mathrm{pH}$

146 8.4, it was highest under 17-day intervals, and at $\mathrm{pH} 8.7$ it declined in the order 17-day $>14$-day $>$ 147 23-day intervals. narrow range by adjusting their $\mathrm{N}$ and/or $\mathrm{P}$ contents in response to environmental changes. For example, the $H_{N: P}$ of $L$. chinensis varied from 3.06 to 9.23 in plants exposed to different $\mathrm{P}$ concentrations, while its ranges under the 14-, 17- and 23-day stress interval regimes were 3.159.23, 3.11-6.83 and 3.06-6.44, respectively, and its peak values occurred at $\mathrm{pH} 8.4,8.4$, and 8.1, respectively (Table 2). L. chinensis plants are thus able to effectively regulate their $N: P$ ratio in the $\mathrm{pH}$ range 8.1 to 8.7 , but less so at $\mathrm{pH} 7.5$ and 9.3 .

\section{The specific growth rate of $L$. chinensis}

The specific growth rate of the plants rapidly increased then decreased as the $\mathrm{N}$ concentration in the substrate increased, peaking at $16 \mathrm{mmol} / \mathrm{L}$ (Fig. 3). This indicates that when L. chinensis plants lack $\mathrm{N}$, initial $\mathrm{N}$ addition will be extremely efficient, but saturating or excessive amounts will not promote (and may even hinder) further growth. Conversely, the plants' specific growth rate first increased, then decreased, and then increased again with increases in environmental $\mathrm{P}$ concentration. Specifically, it was lowest at a $\mathrm{P}$ concentration of $2.4 \mathrm{mmol} / \mathrm{L}$, and higher at both 
1621.2 and $4.8 \mathrm{mmol} / \mathrm{L}$. Thus, high addition of $\mathrm{P}$ is beneficial for plant growth but may lead to

163 wastage of resources. Therefore, the optimum P concentration under our experimental conditions 164 was $1.2 \mathrm{mmol} / \mathrm{L}$.

165 In summary, the threshold concentrations of $\mathrm{N}$ and $\mathrm{P}$ in the substrate solution at which the 166 biomass of L. chinensis began to decrease (or stopped increasing) were 16 and $1.2 \mathrm{mmol} / \mathrm{L}$, 167 respectively. Moreover, plants exposed to $1.2-4.8 \mathrm{mmol} / \mathrm{L} \mathrm{P}$ were mainly restricted by $\mathrm{N}$, while 168 those exposed to 16 and $24 \mathrm{mmol} / \mathrm{L} \mathrm{N}$ were mainly restricted by $\mathrm{P}$, and those exposed to lower concentrations of $\mathrm{P}$ and $\mathrm{N}$ were restricted by $\mathrm{P}$ and $\mathrm{N}$, respectively (Fig. 4). According to the results of the correlation analysis, the specific growth rate of $L$. chinensis and the plant N:P ratio is positively correlated in both N-limited and P-limited environments, and the correlation is slightly stronger under P-restricted conditions, but neither of them passed the significance test. In the $\mathrm{N}$ and $\mathrm{P}$ co-limited environment, the specific growth rate of $L$. chinensis has a positive correlation with the plant $\mathrm{N}: \mathrm{P}$ ratio, and the correlation coefficient is 0.46 , which is significant at the level of 0.01 .

\section{DISCUSSION}

\section{$\mathrm{N}$ and $\mathrm{P}$ contents and the $\mathrm{N}: \mathrm{P}$ ratio in $L$. chinensis}

$\mathrm{N}$ and $\mathrm{P}$ are key nutrients that play major roles in myriad processes in plants and have important effects on one-another's uptake and metabolism (Han et al., 2009). N:P ratios in plants fluctuate within relatively narrow ranges, and variations in their $\mathrm{N}$ and $\mathrm{P}$ contents are restricted by homeostatic mechanisms. Although $\mathrm{P}$ and $\mathrm{N}$ contents can influence each other, $\mathrm{N}$ affects $\mathrm{P}$ contents more strongly than vice versa, putatively due to the overall higher abundance of $\mathrm{N}$ in plants $(\mathrm{Yu}, 2005)$. We found that L. chinensis plants absorbed limited amounts of $\mathrm{P}$ from soils with a low $\mathrm{N}$ content, and changes in the soil's $\mathrm{N}$ contents between 2 and $8 \mathrm{mmol} / \mathrm{L}$ had minor 
185

186

187

effects on the P content of their aboveground parts. However, their P contents were substantially increased by higher $\mathrm{N}$ concentrations in the soil. Similarly, we found that $\mathrm{N}$ contents of aboveground parts of $L$. chinensis are influenced by the environmental P concentration: they changed greatly when the soil's P content was low but remained very similar at high $\mathrm{P}$ concentrations. In summary, P content is the main constraint on plant growth when the soil's $\mathrm{P}$ content is low, but $\mathrm{N}$ content becomes the main constraint of plant growth when the $\mathrm{P}$ content is high.

Our experiment examined saline-alkaline environments with different $\mathrm{pH}$ values. The $\mathrm{N}$ and $\mathrm{P}$ contents in aboveground parts of $L$. chinensis were both high at $\mathrm{pH} 8.4$, indicating that the plants maintained strong control over their $\mathrm{N}: \mathrm{P}$ ratios at this $\mathrm{pH}$ and confirming the previously reported finding that this $\mathrm{pH}$ promotes growth of L. chinensis (Li et al., 2018). L. chinensis can resist mild $\mathrm{pH}$ stress but it is inhibited by strong saline-alkali stress (Yan et al., 2006). At high $\mathrm{pH}$ (8.7 and 9.3), we found that its $\mathrm{P}$ content was relatively high when there were high soil concentrations of either $\mathrm{N}$ (16 or $24 \mathrm{mmol} / \mathrm{L})$ or $\mathrm{P}(2.4$ or $4.8 \mathrm{mmol} / \mathrm{L})$. However, plants need more $\mathrm{P}$ to cope with $\mathrm{pH}$ stress. Plants' nutrient adsorption is related to $\mathrm{pH}$, together with indications that luxury uptake of $\mathrm{N}$ and $\mathrm{P}$ under moderate $\mathrm{pH}$ stress enables some plants (e.g. Rhizoma acori graminei and Lythrum salicaria) to resist strong $\mathrm{pH}$ stress (Cheng et al., 2017).

The $\mathrm{N}$ and $\mathrm{P}$ contents in aboveground parts of $L$. chinensis we observed at various $\mathrm{pH}$ values indicate that $\mathrm{N}$ contents in plants are more sensitive to saline conditions than their $\mathrm{P}$ contents.

\section{Homeostasis characteristics of $\mathrm{N}, \mathrm{P}$, and $\mathrm{N}: \mathrm{P}$ in $L$. chinensis}

Homeostasis theory postulates that plants can adjust their growth rate, and rates of both resource allocation and utilization in mechanisms that maintain their internal homeostasis (Mendez and Karlsson, 2005). Homeostasis is stronger in animals than in plants, and in higher plants than 
208 lower plants (Zeng et al., 2016), suggesting that homeostatic mechanisms have become more 209 powerful over the course of evolutionary history. We found that the homeostasis indices for $\mathrm{N}$ 210 content, P content and the N:P ratio in L. chinensis were within reported ranges for algae, fungi 211 (Sterner and Elser, 2002), and animals (Yu, 2005; Karimi and Folt, 2006). On the basis of experiments on Inner Mongolian grassland and sand culture, Yu et al. (2009) concluded that

213

aboveground parts of $L$. chinensis have slightly higher $H_{N}, H_{P}$ and $H_{N: P}$ values $(5.88-8.80,3.37$ -

6.67 and 4.49-9.46, respectively) than those observed in our study, possibly due to differences in climatic conditions.

We also found that all three homeostasis indexes first increased then decreased with increases in $\mathrm{pH}$. At $\mathrm{pH} 8.1$ and 8.4, they were all high, showing that L. chinensis can maintain stable levels of nutrients in weakly alkaline environments. However, the indices were lower under more strongly alkaline conditions $(\mathrm{pH}>8.7)$, indicating that such conditions have toxic effects. This is consistent with previous observations that saline and alkaline stress has both physiological and biochemical effects on roots and leaves of L. chinensis (Liu et al., 2014).

Another finding is that $\mathrm{H}_{\mathrm{N}: \mathrm{P}}>\mathrm{H}_{\mathrm{N}}>\mathrm{H}_{\mathrm{P}}$, indicating that the stronger homeostasis of $\mathrm{N}$ content than of $\mathrm{P}$ content in plants is mainly due to their significantly higher $\mathrm{N}$ content. Accordingly, homeostasis in zooplankton is reportedly highest for macronutrients, followed by micronutrients, and lowest for non-essential elements (Karimi and Folt, 2006). Since high N contents in plant tissues promote high $\mathrm{P}$ contents and plants' $\mathrm{N}: \mathrm{P}$ ratios vary less than their $\mathrm{N}$ and $\mathrm{P}$ contents, the $\mathrm{N}: \mathrm{P}$ ratio may be subject to stronger homeostasis than either $\mathrm{N}$ or $\mathrm{P}$ individually (Sterner and Elser, 2002). Plants maintain N:P stability by their adjusting resource allocation and utilization of resources. The degree of stability may reflect their environmental adaptability, so the N:P ratio appears to be more important than $\mathrm{N}$ and $\mathrm{P}$ contents in this respect. 
The plants' homeostasis is related to the duration of the incremental increases in salinity-

232

233

234

235

236

237

238

239

240

241

242

243

244

245

246

247

248

249

250

251

252

253

alkalinity stress. With 14-day intervals (rapid changes in alkalinity), the positive effects of a weakly alkaline environment $(\mathrm{pH} 7.5-8.4)$ on leaves of L. chinensis are stronger than those observed with longer intervals: the homeostasis indices of the aboveground parts are relatively high, and further increases in alkalinity (to $\mathrm{pH} 8.7$ or 9.3) induce relatively little damage to leaves. $H_{N: P}$ and $H_{P}$ are strongly affected by changes in the duration of the incremental increases. For example, the variation in $\mathrm{H}_{\mathrm{N}: \mathrm{P}}$ of aboveground parts is higher with 23-day intervals than with either 14- or 17-day intervals (rising to a peak and then quickly falling with increases in $\mathrm{pH}$, as shown in Fig. 2).

\section{Specific growth rate}

Specific growth rates are crucial indicators of organisms' adaptation to (and thus ability to survive and reproduce within) an environment. Clearly, variations in growth capacity can be linked to variations in elemental demand (Moody et al., 2017). Our results confirm previous findings (and intuitive expectations) that adding $\mathrm{N}$ can significantly enhance growth of Ndeficient plants. However, they also show that adding $\mathrm{N}$ can inhibit plants' growth if the environmental content of $\mathrm{N}$ exceeds the plants' requirements. The optimal $\mathrm{N}$ and $\mathrm{P}$ contents in the soil under our experimental conditions were 16 and $1.2 \mathrm{mmol} / \mathrm{L}$, respectively. Adding excess P will not have inhibitory effects, and may even further stimulate growth slightly, but would be a waste of resources.

Plants can absorb elements in soils selectively. Moreover, The N:P ratio has a relatively complex relationship with specific growth rates: they are positively correlated at low specific growth rates, but negatively correlated once the specific growth rate exceeds a certain threshold (Agren, 2004). Additionally, specific growth rates of belowground parts of plants were positively 
254 correlated with N:P under N constraints, but negatively correlated with N:P under P constraints

255 (Yu, 2009). In our experiment, growth of L. chinensis was restricted by both $\mathrm{N}$ and $\mathrm{P}$. The

256 specific growth rate of aboveground parts was positively related to N:P under N constraint or P

257 constraint, but the positive correlation was strengthened under the co-constraint of $\mathrm{N}$ and $\mathrm{P}$. This

258 is consistent with the conclusions of $\mathrm{Yu}$ et al. with respect to the effects of $\mathrm{N}$ constraint, but not

259 those of P constraint. We speculate that this was due to the plant's generally low specific growth

260 rate in the experiment, and also possibly to effects of salinity-alkalinity on the relationships

261 between plant growth and other environmental variables. Although effects of plants' nutrient

262 storage on their specific growth rates have been discussed (Sterner and Elser, 2002; Yu, 2009),

263 the relationship between their specific growth rates and $\mathrm{C}: \mathrm{N}: \mathrm{P}$ ratios clearly requires further

264 study.

265 According to the specific growth rate hypothesis, high amounts of ribosomal RNA (rRNA),

266 and thus $\mathrm{P}$, are needed to synthesize the large quantities of proteins required to sustain high

267 specific growth rates (Sterner and Elser, 2002). Therefore, organisms with high specific growth

268 rates have relatively high $\mathrm{P}$ contents and low N:P ratios. This hypothesis is supported by both

269 theoretical considerations and empirical observations of zooplankton, arthropods, and bacteria

270 (Elser et al., 2003; Watts et al., 2006; Hessen et al., 2007). However, the relationships may be

271 more complex in higher plants. Accordingly, we observed the positive correlation between the

272 specific growth rate and N:P ratio of $L$. chinensis, rather than the negative correlation predicted

273 by the hypothesis. This may have been because we monitored adult L. chinensis plants rather

274 than juveniles, and/or because the specific growth rate of the studied plants was strongly

275 influenced by the variation of several environmental factors ( $\mathrm{N}$ content, $\mathrm{P}$ content, and $\mathrm{pH})$ and

276 thus does not reflect their intrinsic potential specific growth rates. 
277

278

279

280

281

282

284

285

286

287

288

289

290

291

292

\section{CONCLUSION}

The findings presented here demonstrate that $L$. chinensis has the homeostasis ability under a certain degree of salinity-alkalinity stress. And the $\mathrm{N}$ content of $L$. chinensis is more sensitive to the environmental $\mathrm{pH}$ than its $\mathrm{P}$ content. At substrate $\mathrm{pH}$ values of 8.4 and 8.7, L. chinensis possesses good environmental adaptability. In particular, at a substrate $\mathrm{pH}$ of 8.4, L. chinensis were well able to control their contents of $\mathrm{N}$ and $\mathrm{P}$ as well as the $\mathrm{N}: \mathrm{P}$ ratio. Weak alkalinity (pH 7.5-8.4) is beneficial for growth and $\mathrm{N}$ accumulation in L. chinensis, but more strongly alkaline conditions ( $\mathrm{pH} 8.7$ or 9.3) inhibit its growth. At $\mathrm{pH}$ values above 8.7, the interval between stress increments clearly affected the plants' contents of $\mathrm{N}$ and $\mathrm{P}$ as well as the N:P ratio. The relationship between the specific growth rate and N:P ratio may become more complex (not simple linear) because of the salinity-alkalinity stress.

\section{ACKNOWLEDGEMENTS}

This work was supported by the Science and Technology Strategy and Planning Research of Jilin Science and Technology Department (grant no. 20200101119FG). We thank Chenhao Cao, lunian Gao and Xiaowei Han for their assistance during plant cultivation and harvesting. We are grateful to the Associate Editor and one anonymous referee for providing valuable comments.

\section{REFERENCES}

Agren, G.I., 2004. The C : N : P stoichiometry of autotrophs - theory and observations. Ecology Letters 7, 185191.

Bradshaw, C., Kautsky, U., Kumblad, L., 2012. Ecological stoichiometry and multi-element transfer in a coastal ecosystem. Ecosystems 15, 591-603.

Cambardella, C.A., Elliott, E.T., 1993. Carbon and nitrogen distribution in aggregates from cultivated and native grassland soils. Soil Science Society of America Journal 57, 1071-1076.

Cheng, X., Liang, Y., Zhu, H., Chen, X., Yan, B., Zhou, Q., Yu, X., 2017. A hydroponic experiment on response of six plant species to salt stress and their denitrification potentiality. Wetland Science 15, 635-640.

Cooper, S.J., 2008. From Claude Bernard to Walter Cannon. Emergence of the concept of homeostasis. Appetite 51, 419-427. 
Elser, J.J., Acharya, K., Kyle, M., Cotner, J., Makino, W., Markow, T., Watts, T., Hobbie, S., Fagan, W., Schade, J., Hood, J., Sterner, R.W., 2003. Growth rate-stoichiometry couplings in diverse biota. Ecology Letters 6, 936-943.

Elser, J.J., Sterner, R.W., Gorokhova, E., Fagan, W.F., Markow, T.A., Cotner, J.B., Harrison, J.F., Hobbie, S.E., Odell, G.M., Weider, L.W., 2000. Biological stoichiometry from genes to ecosystems. Ecology Letters 3, 540-550.

Güsewell, S., 2004. N : P ratios in terrestrial plants: variation and functional significance. New Phytologist 164, 243-266.

González, A.L., Kominoski, J.S., Danger, M., Ishida, S., Iwai, N., Rubach, A., 2010. Can ecological stoichiometry help explain patterns of biological invasions? Oikos 119, 779-790.

Halvorson, H.M., Fuller, C.L., Entrekin, S.A., Scott, J.T., Evans-White, M.A., 2019. Interspecific homeostatic regulation and growth across aquatic invertebrate detritivores: a test of ecological stoichiometry theory. Oecologia 190, 229-242.

Han, W., Wu, Y., Tang, L., Chen, Y., Li , L., He, J., Fang, J., 2009. Leaf carbon, nitrogen and phosphorus stoichiometry across plant species in Beijing and its periphery. Acta Scientiarum Naturalium Universitatis Pekinensis 45, 855-860.

Hessen, D.O., Jensen, T.C., Kyle, M., Elser, J.J., 2007. RNA responses to N- and P-limitation; reciprocal regulation of stoichiometry and growth rate in Brachionus. Functional Ecology 21, 956-962.

Karimi, R., Folt, C.L., 2006. Beyond macronutrients: element variability and multielement stoichiometry in freshwater invertebrates. Ecology Letters 9, 1273-1283.

Kerr, J.G., 2017. Multiple land use activities drive riverine salinization in a large, semi-arid river basin in western Canada. Limnology and Oceanography 62, 1331-1345.

Kooijman, S., 1995. The stoichiometry of animal energetics. Journal of Theoretical Biology 177, 139-149.

Li, B., Liu, G., Yang, J., Wang, X., 2017a. Effects of agronomic measures on soil nutrients in light-moderate salinization blocked farmland. Chinese Journal of Soil Science 48, 190-194.

Li, J., Hou, X., Ma, W., Li, X., Ding, Y., Wu, Z., Guo, F., Li, Y., Zhao, J., 2019. Effect of interspecies relationships on nitrogen and phosphorus uptake and utilization efficiency of Leymus chinensis and Artemisia frigida under different phosphorus environment. Chinese Journal of Grassland 41, 17-24.

Li, X., 2000. The alkili-saline land and agricultural sustainable development of the western Songnen plain in China. Scientia Geographica Sinica 20 51-55.

Li, Y., Li, Q., Liu, H., Li, S., Wang, Y., Liu, Y., 2018. Ecological stoichiometry-based study of the influence of soil saline-alkali stress on nutrient homeostasis in L. chinensis. Ecotoxicology and Environmental Safety 165, 243249.

Liu, B., Kang, C., Wang, X., Bao, G., 2014. Physiological and biochemical response characteristics of Leymus chinensis to saline-alkali stress. Transactions of the Chinese Society of Agricultural Engineering 30, 166-173.

Mendez, M., Karlsson, P.S., 2005. Nutrient stoichiometry in Pinguicula vulgaris: Nutrient availability, plant size, and reproductive status. Ecology 86, 982-991.

Meunier, C.L., Malzahn, A.M., Boersma, M., 2014. A new approach to homeostatic regulation: towards a unified view of physiological and ecological concepts. PloS one 9, e107737.

Moody, E.K., Rugenski, A.T., Sabo, J.L., Turner, B.L., Elser, J.J., 2017. Does the Growth Rate Hypothesis apply across temperatures? Variation in the growth rate and body phosphorus of neotropical benthic Grazers. Front. Environ. Sci. 5, 11. 
Mulder, C., Elser, J.J., 2009. Soil acidity, ecological stoichiometry and allometric scaling in grassland food webs. Global Change Biology 15, 2730-2738.

Normand, A.E., Smith, A.N., Clark, M.W., Long, J.R., Reddy, K.R., 2017. Chemical composition of soil organic matter in a subarctic peatland: Influence of shifting vegetation communities. Soil Science Society of America Journal 81, 41-49.

Sanders, A.J., Taylor, B.W., 2018. Using ecological stoichiometry to understand and predict infectious diseases. Oikos 127, 1399-1409.

Sterner, R.W., Elser, J.J., 2002. Ecological stoichiometry: the biology of elements from molecules to the biosphere. Princeton University Press.

Tang, M., Xiao, M., Yuan, H., Wang, G., Liu, S., Zhu, Z., GE, T., Wu, J., 2018. Effect of $\mathrm{CO}_{2}$ doubling and different plant growth stages on rice carbon, nitrogen, and phosphorus and their stoichiometric ratios. Environmental Science 39, 5708-5716.

Wardle, D.A., Walker, L.R., Bardgett, R.D., 2004. Ecosystem properties and forest decline in contrasting longterm chronosequences. Science 305, 509-513.

Watts, T., Woods, H.A., Hargand, S., Elser, J.J., Markow, T.A., 2006. Biological stoichiometry of growth in Drosophila melanogaster. Journal of Insect Physiology 52, 187-193.

Wu, C., Huang, C., Liu, G.H., Liu, Q., 2016. Spatial prediction of soil salinity in the Yellow River Delta based on geographically weighted regression. Resources Science 38, 704-713.

Yan, H., Zhao, W., Yin, S., Shi, D., Zhou, D., 2006. Different physiological responses of Aneurolepidiumchinense to $\mathrm{NaCl}$ and $\mathrm{Na}_{2} \mathrm{CO}_{3}$. Acta Prataculturae Sinica 15, 49-55.

$\mathrm{Yu}, \mathrm{Q} ., 2005$. The study on the homeostasis and growth rate of a higher plant and their mechanism Master's thesis, Gansu Agricultural University, Lanzhou.

Yu, Q., 2009. Ecological stoichiometric study on vascular plants in the Inner Mongolia steppe. Doctoral dissertation, Institute of Botany, the Chinese Academy of Sciences.

Yu, Q., Elser, J.J., He, N., Wu, H., Chen, Q., Zhang, G., Han, X., 2011. Stoichiometric homeostasis of vascular plants in the Inner Mongolia grassland. Oecologia 166, 1-10.

Zeng, Q., Li, X., Dong, Y., An, S., Darboux, F., 2016. Soil and plant components ecological stoichiometry in four steppe communities in the Loess Plateau of China. Catena 147, 481-488.

Zhang, D., Wang, W., Zheng, H., Ren, Z., Zhai, C., Tang, Z., Shen, G., He, X., 2017. Effects of urbanization intensity on forest structural-taxonomic attributes, landscape patterns and their associations in Changchun, Northeast China: Implications for urban green infrastructure planning. Ecological Indicators 80, 286-296.

Zheng, C., Wang, Y., Sun, H., Wang, X., Gao, Y., 2017. Effects of clipping on nitrogen allocation strategy and compensatory growth of Leymus chinensis under saline-alkali conditions. Chinese Journal of Applied Ecology 28, 2222-2230. 


\section{Table $\mathbf{1}$ (on next page)}

Saline-alkali stress treatments, including durations of exposure to each $\mathrm{pH}$, dates of exposure, and harvest dates.

Notes: There were 10 nutrient treatments and a total of 90 pots were used in the experiment. The salt-alkali stress experiment at incremental interval 23 days with the $\mathrm{pH}$ of 9.3 was not carried out due to the sudden drop of local temperature at the end of October. 


\begin{tabular}{ccccc}
\hline N-P level & Duration (days) & $\mathrm{pH}$ & Dates of exposure & Harvest date \\
\hline & & 7.5 & $2017 / 8 / 07-2017 / 8 / 17$ & $2017 / 8 / 18$ \\
& & 8.1 & $2017 / 8 / 18-2017 / 8 / 31$ & $2017 / 9 / 01$ \\
$3 \times$ N1-P & & 8.4 & $2017 / 9 / 01-2017 / 9 / 14$ & $2017 / 9 / 15$ \\
$3 \times$ N2-P & & 8.7 & $2017 / 9 / 15-2017 / 9 / 28$ & $2017 / 9 / 29$ \\
$3 \times$ N3-P & & 9.3 & $2017 / 9 / 29-2017 / 10 / 12$ & $2017 / 10 / 13$ \\
$3 \times$ N4-P & & 7.5 & $2017 / 8 / 07-2017 / 8 / 22$ & $2017 / 8 / 23$ \\
$3 \times$ N5-P & Incremental interval 17 days & 8.1 & $2017 / 8 / 23-2017 / 9 / 08$ & $2017 / 9 / 09$ \\
$3 \times$ N-P1 & & 8.4 & $2017 / 9 / 09-2017 / 9 / 25$ & $2017 / 9 / 26$ \\
$3 \times$ N-P2 & & 8.7 & $2017 / 9 / 26-2017 / 10 / 12$ & $2017 / 10 / 13$ \\
$3 \times$ N-P3 & & 9.3 & $2017 / 10 / 13-2017 / 11 / 05$ & $2017 / 11 / 06$ \\
$3 \times$ N-P4 & & 7.5 & $2017 / 8 / 07-2017 / 8 / 27$ & $2017 / 8 / 28$ \\
$3 \times$ N-P5 & & 8.1 & $2017 / 8 / 28-2017 / 9 / 19$ & $2017 / 9 / 20$ \\
& & 8.4 & $2017 / 9 / 20-2017 / 10 / 12$ & $2017 / 10 / 13$ \\
& Incremental interval 23 days & 8.7 & $2017 / 10 / 13-2017 / 11 / 05$ & $2017 / 11 / 06$ \\
& & 9.3 & & No Harvest \\
\hline
\end{tabular}

2 


\section{Table 2 (on next page)}

Homeostasis indices $(H)$ of aboveground parts of $L$. chinensis, and their linear regression correlation coefficients $\left(R^{2}\right)$, under the indicated saline-alkali stress treatments.

Notes: "-" indicates that no valid data were obtained, and "*" indicates an outlier. 


\begin{tabular}{|c|c|c|c|c|c|c|c|}
\hline \multirow[b]{2}{*}{$\mathrm{pH}$} & \multicolumn{2}{|c|}{ Incremental interval 14 days } & \multicolumn{2}{|c|}{ Incremental interval 17 days } & \multicolumn{3}{|c|}{ Incremental interval 23 days } \\
\hline & $H_{\mathrm{N}}$ & $\mathrm{R}^{2}$ & $H_{\mathrm{N}}$ & $\mathrm{R}^{2}$ & $H_{\mathrm{N}}$ & $\mathrm{R}^{2}$ & $\begin{array}{l}\text { Average } \\
H_{\mathrm{N}} \\
\end{array}$ \\
\hline 7.5 & 3.23 & 0.93 & 3.20 & 0.92 & 3.81 & 0.93 & 3.41 \\
\hline 8.1 & $5.53 *$ & $0.22 *$ & 3.70 & 0.98 & 3.87 & 0.95 & 4.37 \\
\hline 8.4 & 7.25 & 0.95 & 5.36 & 0.83 & $15.58^{*}$ & $0.34^{*}$ & 6.31 \\
\hline 8.7 & 5.57 & 0.64 & 2.35 & 0.96 & 3.19 & 0.93 & 3.70 \\
\hline \multirow[t]{2}{*}{9.3} & 3.10 & 0.89 & - & - & - & - & 3.10 \\
\hline & $H_{\mathrm{P}}$ & $\mathrm{R}^{2}$ & $H_{\mathrm{P}}$ & $\mathrm{R}^{2}$ & $H_{\mathrm{P}}$ & $\mathrm{R}^{2}$ & $\begin{array}{l}\text { Average } \\
H_{\mathrm{P}}\end{array}$ \\
\hline 7.5 & 2.97 & 0.99 & 3.19 & 0.99 & 3.60 & 0.92 & 3.25 \\
\hline 8.1 & 5.33 & 0.80 & 3.92 & 0.96 & 4.10 & 0.79 & 4.45 \\
\hline 8.4 & 3.84 & 0.70 & 4.35 & 0.84 & 3.65 & 0.85 & 3.95 \\
\hline 8.7 & 3.97 & 0.96 & 4.90 & 0.95 & 2.60 & 0.94 & 3.82 \\
\hline \multirow[t]{2}{*}{9.3} & 2.84 & 0.99 & 2.64 & 0.90 & - & - & 2.74 \\
\hline & $H_{\mathrm{N}: \mathrm{P}}$ & $\mathrm{R}^{2}$ & $H_{\mathrm{N}: \mathrm{P}}$ & $\mathrm{R}^{2}$ & $H_{\mathrm{N}: \mathrm{P}}$ & $\mathrm{R}^{2}$ & $\begin{array}{l}\text { Average } \\
H_{\mathrm{N}: \mathrm{P}}\end{array}$ \\
\hline 7.5 & 3.15 & 0.96 & 5.47 & 0.82 & 3.06 & 0.95 & 3.89 \\
\hline 8.1 & 4.84 & 0.82 & 3.68 & 0.93 & 6.44 & 0.79 & 4.98 \\
\hline 8.4 & $9.22 *$ & $0.31^{*}$ & 6.83 & 0.86 & 4.76 & 0.89 & 6.94 \\
\hline 8.7 & 5.27 & 0.84 & 5.89 & 0.91 & 3.94 & 0.84 & 5.03 \\
\hline 9.3 & 3.46 & 0.86 & 3.11 & 0.96 & - & - & 3.29 \\
\hline
\end{tabular}


Figure 1

Relationships between the $\mathrm{N}$ and $\mathrm{P}$ contents, and $\mathrm{N}: \mathrm{P}$ ratios of $L$. chinensis plants and the intervals between saline-alkali stress increments. Solid circles, hollow circles and triangles refer to intervals of 14,17 , and 23 days, respectively.

Solid circles, hollow circles and triangles refer to intervals of 14, 17, and 23 days, respectively. Error bars are standard deviations. 

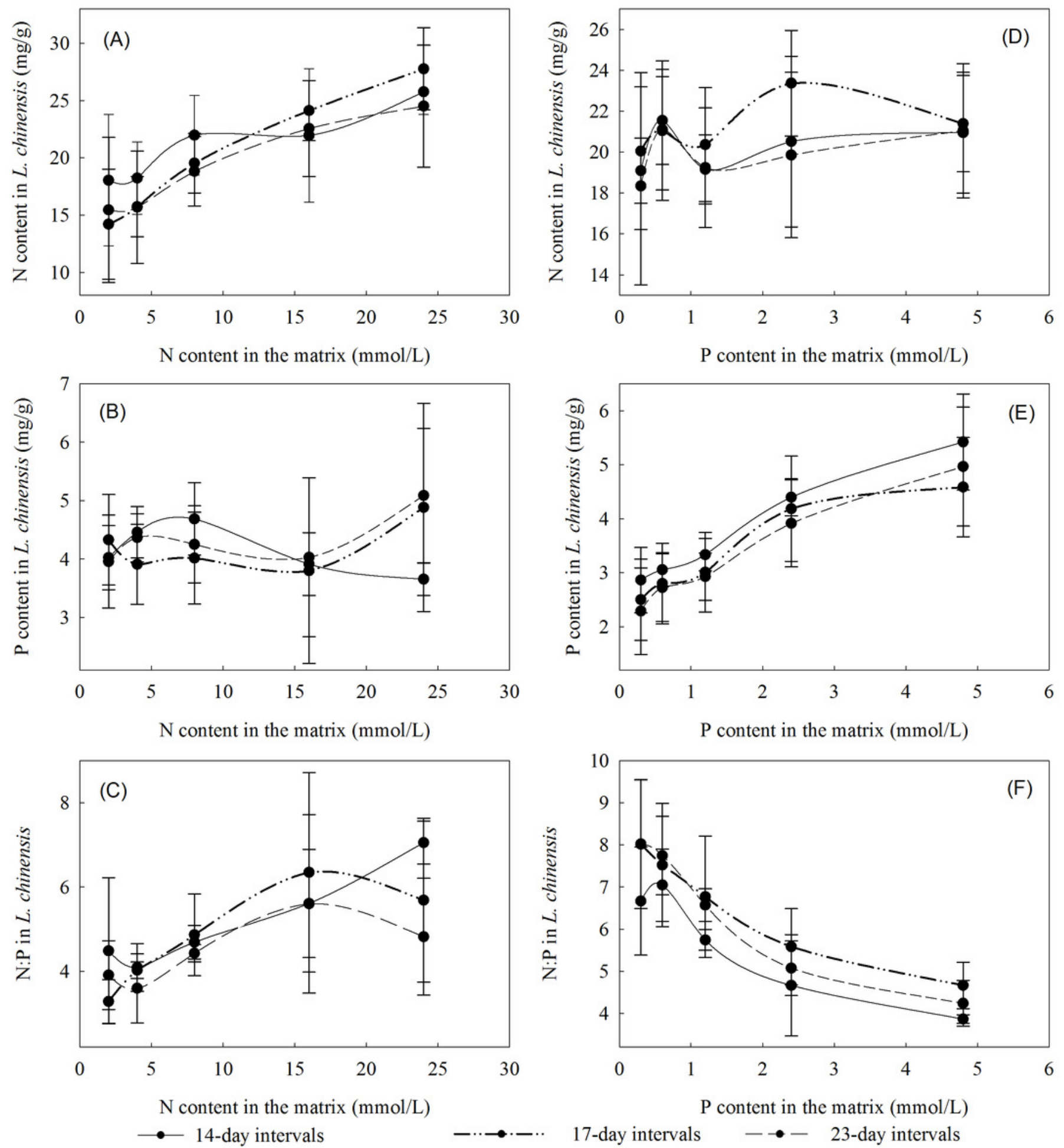

17-day intervals $\quad-\rightarrow-\quad 23$-day intervals 
Figure 2

Homeostasis indices of $L$. chinensis at the indicated $\mathrm{pH}$ values and saline-alkali stress incremental intervals.

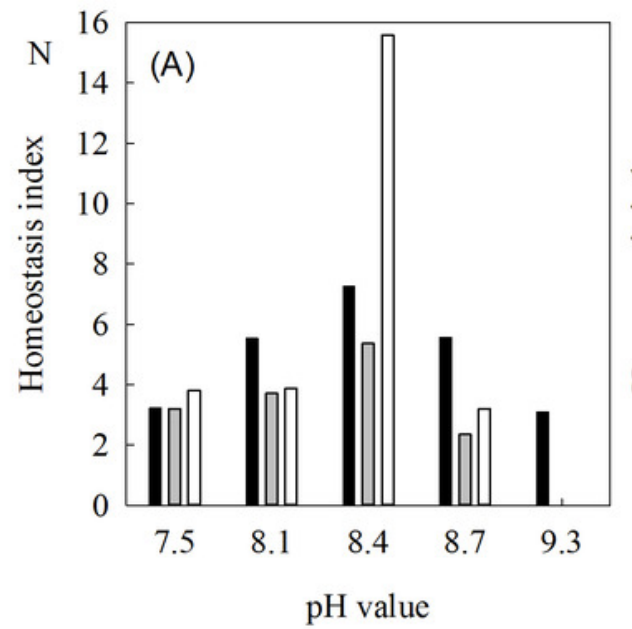

Incremental interval 14 days

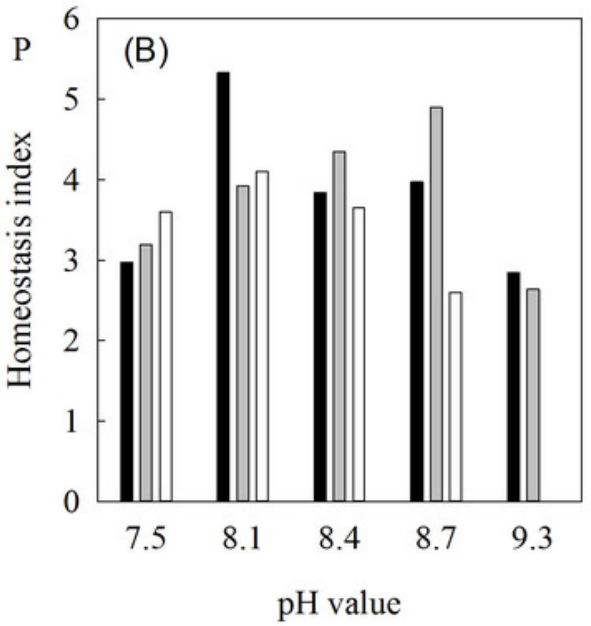

$\sqsubset$ Incremental interval 17 days

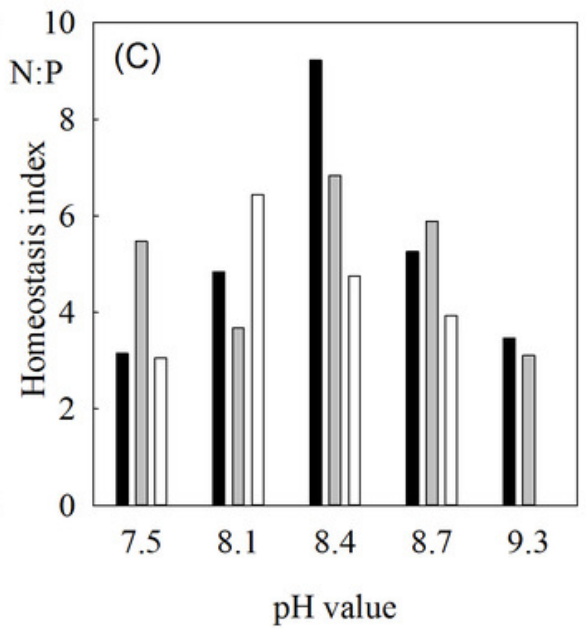

Incremental interval 23 days 
Figure 3

Specific growth rates of $L$. chinensis at the indicated environmental $\mathrm{N}$ and $\mathrm{P}$ concentrations, and $\mathrm{pH}$.
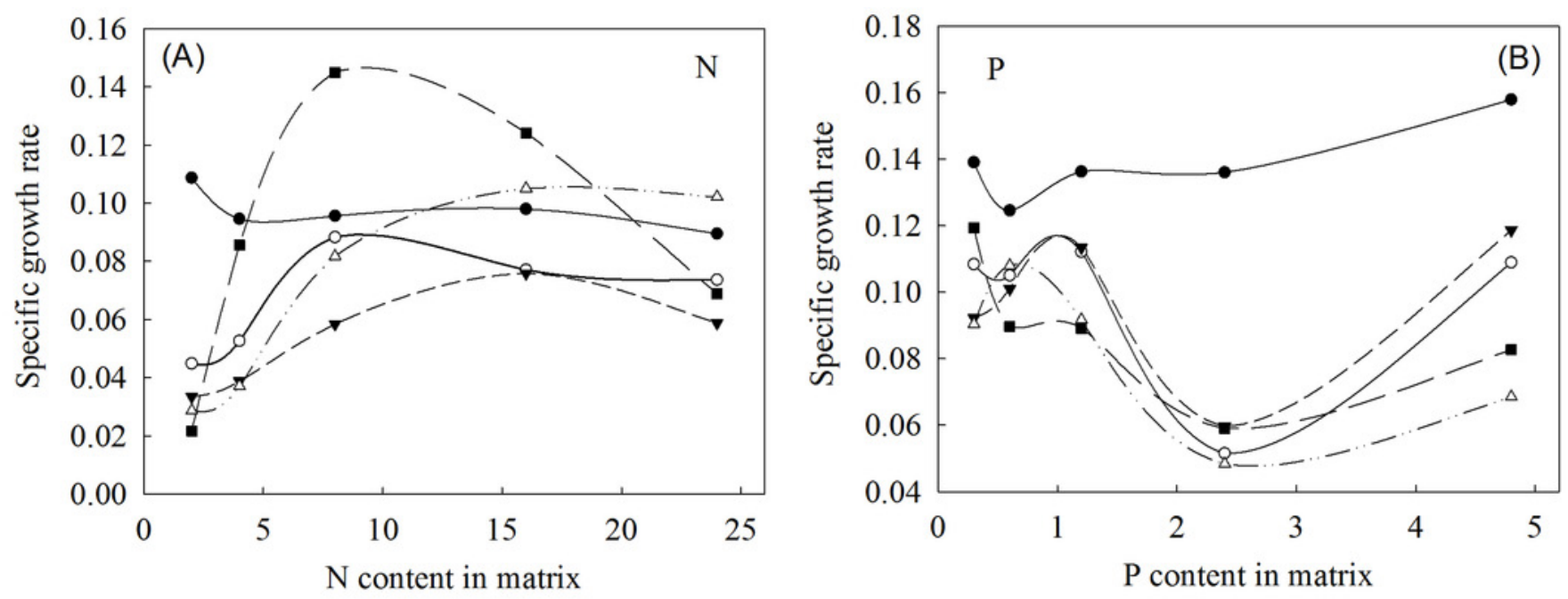

$\bullet 7.5 \quad \multimap 8.1$
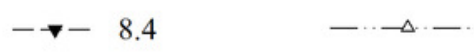

8.7

9.3 
Figure 4

Relationship between the specific growth rate and the N:P ratio in the aboveground parts of $L$. chinensis.

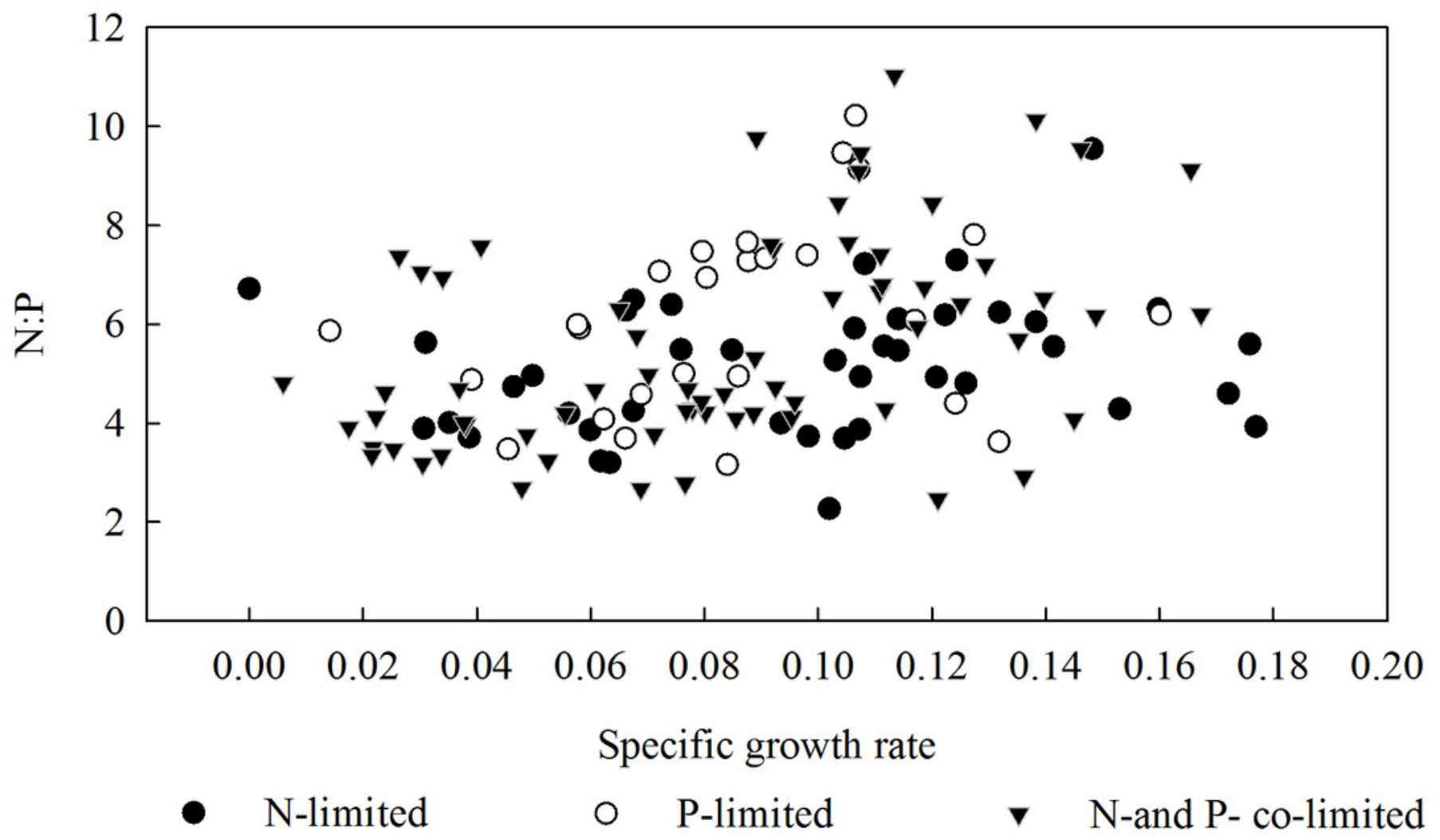

